\title{
Experiences in the treatment of refractory chylothorax associated with lymphoproliferative disorders
}

\author{
Jana Pospiskova1', Lukas Smolej, ${ }^{1,2}$, David Belada ${ }^{1,2}$, Martin Simkovic ${ }^{1,2}$, Monika Motyckova ${ }^{1,2}$, Alice Sykorova ${ }^{1}$, \\ Pavla Stepankova ${ }^{1}$ and Pavel Zak ${ }^{1,2^{*}}$ (D)
}

\begin{abstract}
Background: Chylothorax is a rare condition which can be associated with malignant lymphoproliferative disorders (LPDs). We retrospectively analyzed the results of the conservative treatment of 10 patients with persistent nontraumatic malignant chylothorax.

Results: Conservative treatment lead to a decline of chylothorax after mean of 66 days and consisted of the treatment of the underlying disease and of simultaneous long-term supportive care (drainage of the thoracic cavity, dietary measures and nutrition management). In most cases (80\%), chylothorax disappeared only after a successful therapeutic response of the underlying disease. Low-dose radiotherapy had very good effects in two patients.

Conclusion: Conservative treatment of malignant chylothorax can be considered a suitable method. Based on our results, successful treatment of the lymphoproliferative disorder seems to be a very important factor for the disappearance of chylothorax.
\end{abstract}

Keywords: Chylothorax, Non-Hodgkin's lymphoma, Chronic lymphocytic leukemia, Radiotherapy, Thoracic duct

\section{Background}

Chylothorax is the accumulation of chyle in the pleural cavity. One of the causes of the disturbed function of the thoracic duct is the direct infiltration or compression by a tumor [1-3]. As a result, chyle leaks and accumulates within the pleural cavity. This complication is rare but it may pose a serious problem. Massive effusion may lead to respiratory difficulties, depending on the amount and rate of refilled liquid. The chyle contains a large quantity of fat and of fat-soluble vitamins, proteins, electrolytes and $\mathrm{T}$ lymphocytes. The failure of chyle resorption or chyle loss during evacuation may result in serious malnutrition, immune system dysfunction, dehydration and hypovitaminosis [4]. The aim of this article is to present our experience with the conservative management of non-traumatic malignant chylothorax.

\footnotetext{
* Correspondence: pavel.zak@fnhk.cz

${ }^{1} 4$ th Department of Internal Medicine - Hematology, University Hospital, Sokolska Street 581, 5005 Hradec Kralove, Czech Republic

${ }^{2}$ Faculty of Medicine in Hradec Králové, Charles University Prague, Hradec Kralove, Czech Republic
}

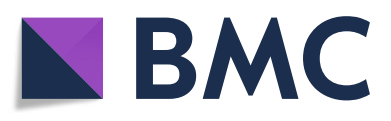

(c) The Author(s). 2019 Open Access This article is distributed under the terms of the Creative Commons Attribution 4.0 International License (http://creativecommons.org/licenses/by/4.0/), which permits unrestricted use, distribution, and

reproduction in any medium, provided you give appropriate credit to the original author(s) and the source, provide a link to the Creative Commons license, and indicate if changes were made. The Creative Commons Public Domain Dedication waiver (http://creativecommons.org/publicdomain/zero/1.0/) applies to the data made available in this article, unless otherwise stated.

\section{Patients and methods}

Between January 2005 and December 2014, ten patients with malignant chylothorax were diagnosed and treated at our department. In these patients mediastinal lymphadenopathy associated with active lymphoproliferative disease was documented and/or malignant cells in effusion which corresponded to the underlying disease were confirmed by cytological and immunophenotypic techniques. Initially, all of the patients with chylothorax required repeated punctures or drainage because of breathing difficulties. Every patient needed 1 to 6 pleural interventions, usually 3 or 4 per each patient (the median was 3.5). Chest radiograph and/or computed tomography of the chest were performed in all the patients to assess the morphological changes of the thorax and to simultaneously evaluate disease activity. Ultrasound of the pleural cavities was performed before thoracentesis. Chylothorax was suspected due to appearance of a milky or opalescent effusion. Because up to $50 \%$ cases of chylothorax do not have this characteristic appearance $[1,5]$, the diagnosis was always verified or confirmed by 
biochemical methods. The diagnosis of chylothorax was made when the concentration of triglyceride in pleural fluid was greater than $1.24 \mathrm{mmol} / \mathrm{l}(110 \mathrm{mg} / \mathrm{dl})$, when the fluid to serum triglyceride ratio was greater than 1 , and the fluid to serum cholesterol ratio was less than 1 [6]. Pseudochylothorax was differentiated from chylothorax based on the level of triglycerides in the pleural fluid. The triglyceride concentration less than 0.56 $\mathrm{mmol} / \mathrm{l}(50 \mathrm{mg} / \mathrm{dl})$ and the cholesterol greater than 5.18 $\mathrm{mmol} / \mathrm{l} \quad(200 \mathrm{mg} / \mathrm{dl}) \quad($ cholesterol/triglyceride ratio $>1)$ indicate pseudochylothorax $[1,7,8]$.

Persistent chylothorax was considered when 2 weeks of therapy failed to stop chyle production $[1,9]$. Afterwards, the efficacy of the chemotherapy was reviewed and computed tomography of the chest was performed again. The results were used to reconsider the next course of treatment.

\section{Results}

Four of the patients had chronic lymphocytic leukemia / small lymphocytic lymphoma (CLL/SLL), five had follicular lymphoma (FL), and one had non-Hodgkin's peripheral T-cell lymphoma - not otherwise specified (PTCL - NOS). None of the CLL patients developed Richter's transformation. At the time of diagnosis, the median age of the patients was 66 years (95\% confidence interval, 57.5-69.7 years) (Table 1). In 8 of the 10 patients, the daily volume of the drained chyle exceeded $1000 \mathrm{ml}$ at least once during the first 7 days. In 4 of the 10 patients the loss was even greater and amounted to more than $1000 \mathrm{ml}$ in 4 successive days during the initial seven-day period (Table 3 ).

All patients were started on antineoplastic therapy depending on the type of lymphoproliferation (Table 2). Simultaneously, the conservative treatment of chylothorax which involves the puncture and drainage of chyle was initiated. Eight patients received complete

Table 1 List of the patients with malignant chylothorax

\begin{tabular}{lllllll}
\hline Patient & Age (years) & Sex & Diagnosis & Stage & $\mathrm{M}-\mathrm{L}$ & $\mathrm{R}-\mathrm{L}$ \\
\hline 1. & 55 & female & $\mathrm{CLL}$ & IV & yes & yes \\
2. & 72 & male & $\mathrm{CLL}$ & 0 & yes & yes \\
3. & 65 & male & $\mathrm{CLL}$ & ॥ & yes & yes \\
4. & 71 & male & $\mathrm{SLL} / \mathrm{CLL}$ & IVA & yes & yes \\
5. & 62 & female & $\mathrm{FL}$ & IIIB & yes & yes \\
6. & 67 & male & $\mathrm{FL}$ & IVA & yes & yes \\
7. & 60 & male & $\mathrm{FL}$ & IVB & yes & no \\
8. & 72 & female & $\mathrm{FL}$ & IVB & yes & yes \\
9. & 45 & male & $\mathrm{FL}$ & IVA & yes & yes \\
10. & 67 & male & $\mathrm{PTCL}, \mathrm{NOS}$ & IVB & yes & yes \\
\hline
\end{tabular}

Age - at the time of diagnosis; stage - clinical stage (CLL - according to Rai; FL, SLL, PTCL, NOS - Ann Arbor classification); M-L - mediastinal lymphadenopathy; R-L - retroperitoneal lymphadenopathy parenteral nutrition with the required levels of liquid and minerals. Seven patients were on a low-fat diet; 3 patients refused this diet. Two patients were hospitalized only briefly to undergo drainage of the chylous effusion and to receive chemotherapy. They did not show any signs of malnutrition and were treated mainly in an out-patient setting. Therefore, complete parenteral nutrition was not necessary. Reduced chyle production improves the spontaneous healing of the lymphatic system. A low-fat diet is recommended to reduce chyle production. This diet may contain medium chain triglycerides (MCT) which are absorbed directly into the bloodstream through the portal vein (Table 3). The local application of streptokinase with premedication of hydrocortisone was used in 3 patients in order to disturb the pleural adhesions. They already had chest tube for drainage of chylous effusion. None of them had empyema. All of these patients had a protracted course of the disease accompanied by several infectious complications and the formation of adhesions. Management of combination chemotherapy regimen for each patient is summarized in Table 2. In one patient with CLL prolonged and significant secretions from the chest drains continued despite a reduced-fat diet and the suppression of CLL activity, the thoracic duct was irradiated with a total dose of 9 Gy in 5 fractions. This was a very effective measure which lead to decreased secretion of chyle enabling the removal of the chest drain on the 26th day since the end of the irradiation. The patient has not experienced relapse of CLL or chylothorax since (Fig. 1). The total time of this patient's treatment of the chylothorax was 125 days. The patient with SLL had a serosanguinous appearance of the pleural effusion but its biochemical characteristics clearly met the chylothorax criteria $[1,7,8]$.

One patient with FL suffered chylothorax as part of the first relapse of FL. The patient received a FCR regimen and the subsequent irradiation of para-aortic and mediastinal lymph nodes with a dose of 4 Gy in 2 fractions, which led to the clearance of chylous effusion (Table 2, patient 7) [10,11]. Two years later, the patient experienced a chylothorax relapse without signs of an active lymphoma. In this patient the second progression of chylothorax was possibly linked to the previous irradiation of para-aortic and mediastinal lymph nodes. The combination of drainage and dietary measures resulted in the clearance of chylous secretion after 69 days.

In all of these patients suppression of chylothorax was successful. The median time of its clearance was 73 days (95\% CI 42.5-89.1 days). Ninety percent of the occurrence of chylothorax was linked to the activity of malignant lymphoproliferation accompanied by mediastinal lymphadenopathy and/or the presence of cancer cells in chylous effusion. The effective treatment of the 
Table $\mathbf{2}$ List of the treatments in patients with malignant chylothorax

\begin{tabular}{llllll}
\hline Patient & Chemotherapy & Low-fat diet & Parenteral nutrition & RT & Chylothorax treatment duration (days) \\
\hline 1. & FCR & yes & yes & no & 82 \\
2. & FCR, R-Dex & yes & yes & no & 87 \\
3. & FCR, RCD, R-CHOP & yes & yes & yes & 125 \\
4. & FCR & no & no & no & 18 \\
5. & obinutuzumab+bendamustine & no & yes & no & 25 \\
6. & obinutuzumab+bendamustine & yes & yes & no & 82 \\
7. & FCR & yes & yes & yes & 69 \\
8. & R-CHOP & yes & yes & no & 58 \\
9. & R-CHOP/R-megaCHOP, R-ESHAP/R-GDP, 2x ASCT & yes & yes & no & 35 \\
10. & GDP & no & no & no & 77 \\
\hline
\end{tabular}

ASCT autologous stem cell transplantation, $R T$ radiotherapy

malignant disease usually also resulted in the clearance of chylous secretion $[1,12]$. The second progression of chylothorax was unclear in one patient only (10\%), which was associated with the completed radiotherapy of para-aortic and mediastinal lymph nodes. The management included the treatment of both the underlying disease and chylothorax with appropriate chemoimmunotherapy regimens (FCR, R-dex, RCD, R-CHOP, GDP, R-GDP, obinutuzumab + bendamustine, R-ESHAP, and R-mega-CHOP. All treatment regimens are summarized in Table 2). All of the patients required an initial pleural puncture/drainage due to respiratory difficulties. To influence the chylous secretion, a low-fat diet was used in $70 \%$ of the patients and parenteral nutrition in $80 \%$ of the patients. Radiotherapy was used in two patients only (20\%). In one case, irradiation to the thoracic duct with a total dose of 9 Gy in 5 fractions was performed with a very good result. In the other patient, the para-aortic and mediastinal lymph nodes were irradiated with $4 \mathrm{~Gy}$ in 2 fractions [10,11]. A longterm low-fat diet was not followed or observed by 4 of the 7 patients $(57 \%)$ and three patients refused the dietary measures at the beginning of the treatment.
Octreotide/somatostatin is used mainly to treat chylothorax in infants and in patients with traumatic chylothorax [13, 14] and it was not included in our treatment options. Surgical or interventional radiologic approaches which have been on the increase recently were not used due to their narrow specialization and limited availability [8].

The course of chyle loss through chest drains due to changes in conservative treatment in the most problematic patient is shown in a chart (Fig. 1, patient 3). This patient was treated for CLL and his chylothorax lasted for 125 days. The prolonged and substantial loss of chyle led to the use of several treatment options with regard to both chylothorax and CLL. The chemotherapeutic regimen was converted from FCR to RCD and subsequently to $\mathrm{R}-\mathrm{CHOP}$ and dietary measures were altered repeatedly. It was mainly the dietary measures that were poorly tolerated by the patient. Considering the stationary chylous loss after several days of a low-fat diet and nil per os status with simultaneous parenteral nutrition the patient's requests for a change in diet were accepted to a less strict diet. Eventually, irradiation of the thoracic

Table 3 Course of chylothorax treatment and chyle loss through drains

\begin{tabular}{|c|c|c|c|c|}
\hline Patient & $\begin{array}{l}\text { Initial drainage or puncture } \\
\text { for dyspnea (yes-no) }\end{array}$ & $\begin{array}{l}\text { Loss greater than } 1000 \mathrm{ml} / \text { day at } \\
\text { least once during the first } 7 \text { days }\end{array}$ & $\begin{array}{l}\text { Loss greater than } 1000 \mathrm{ml} / \text { day in } 4 \\
\text { successive days during the first } 7 \text { days }\end{array}$ & $\begin{array}{l}\text { Need for drainage after } \\
14 \text { days of treatment }\end{array}$ \\
\hline 1. & yes & yes & no & no \\
\hline 2. & yes & yes & no & yes \\
\hline 3. & yes & yes & yes & yes \\
\hline 4. & yes & yes & yes & yes \\
\hline 5. & yes & yes & no & no \\
\hline 6. & yes & no & no & no \\
\hline 7. & yes & yes & no & yes \\
\hline 8. & yes & yes & yes & yes \\
\hline 9. & yes & yes & yes & no \\
\hline 10. & yes & no & no & no \\
\hline
\end{tabular}




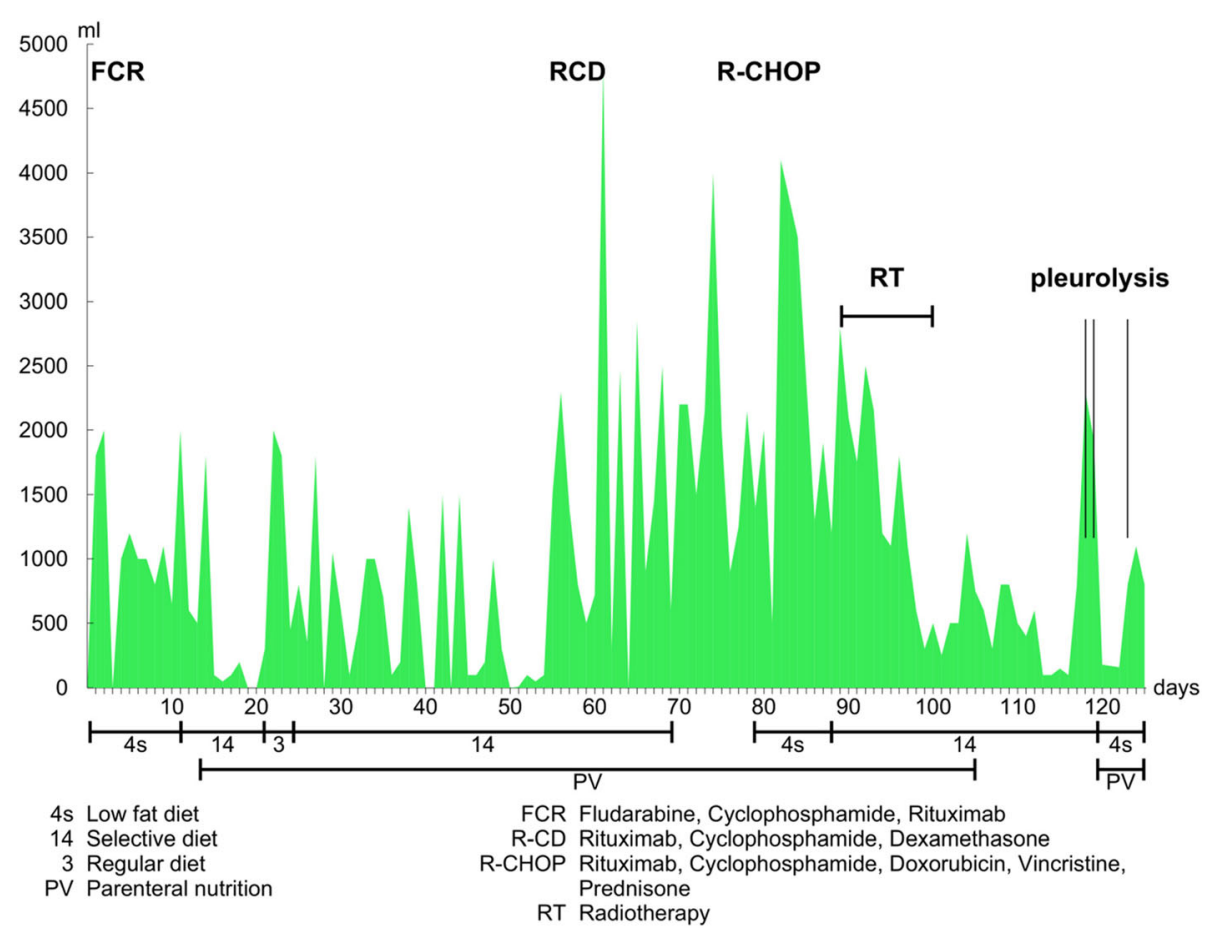

Fig. 1 Dependency of drained chylous fluid volume on supportive and effective anticancer treatment. $4 \mathrm{~s} \mathrm{Low} \mathrm{fat} \mathrm{diet.} \mathrm{FCR:} \mathrm{fludarabine,}$ cyclophosphamide, rituximab. 14 Selection diet. RCD: rituximab, cyclophosphamide, high-dose dexamethasone. 3 Regular diet. R-CHOP: rituximab, cyclophosphamide, doxorubicin, vincristine and prednisone. PN Parenteral nutrition. RT Radiotherapy

duct was used. On the 26th day since the end of the irradiation, the drainage could be terminated and the patient was discharged.

\section{Discussion}

Malignant chylothorax represents more than $50 \%$ of the cases of non-traumatic chylothorax, with most of them being caused by lymphoproliferative disorders [1]. We assume that in the cases described in this article, the function/integrity of the thoracic duct and the subsequent leakage of lymph or impaired drainage was due to infiltration or external compression by a tumor [3]. The treatment of chylothorax is usually long and depends on the type of chylothorax, its duration, extent of chyle loss, and the overall condition of the patient. It appears that the crucial measures in the treatment of malignant chylothorax include effective cancer therapy $[2,12,15]$ and supplementary interventions like parenteral nutrition, the management of concomitant infectious complications as well as rehabilitation [8].

The shortest and the longest activity of chylothorax in our cohort were 18 and 125 days, respectively. The length of the treatment was evaluated with regard to the necessity to perform puncture/drainage due to respiratory difficulties. A small amount of non-refilling fluid in pleural cavities was often persistent even many weeks after treatment but it did not affect the patients' everyday life. Therefore, we considered the chylothorax to be cured when chyle was not refilled.

Teng et al. [2] described the treatment of malignant chylothorax in a 20-year study of 18 patients (19912011); in 11 of them malignant chylothorax was caused by a lymphoproliferative disease (61\%) and in 7 of them by a solid tumor (39\%). Indolent lymphomas occurred more often ( 7 follicular lymphomas, 1 mantle cell lymphoma, 1 lymphoplasmacytic lymphoma) than aggressive lymphomas (1 diffuse large B-cell lymphoma, 1 lymphoblastic lymphoma). In our cohort of 10 patients with lymphoproliferative diseases observed for a period of 9 years (2005-2014), indolent lymphoproliferative disorders (5 follicular lymphomas, 4 chronic lymphocytic leukemia/small lymphocytic lymphomas) were also more frequent than aggressive lymphomas (1 non-Hodgkin peripheral T-cell lymphoma not otherwise specified). Compared to Teng et al., our experience also implies that the main factor of the treatment of malignant chylothorax is whether anticancer therapy is effective. Chylothorax cleared in most patients (80\%) only after reaching response of the hemato-oncological disease which had caused thoracic duct damage. In the cohort presented by Teng et al. chylothorax cleared simultaneously with establishing the complete remission of lymphoproliferation in 6 out of 11 patients (55\%). 
Doerr et al. of Mayo Clinic [16] analyzed the etiology of chylothorax in a study of 203 patients over 20 years (January 1980 - December 2000). Malignant chylothorax was reported only in 34 patients (16.7\%), 23 of them were patients with a lymphoma (11.3\%, 20 had non-Hodgkin's lymphoma and 3 had Hodgkin lymphoma), 5 had chronic lymphocytic leukemia and 6 suffered from another malignity (5 had metastatic disease and 1 had lung carcinoma). Like in our cohort, Doerr et al. observed that chylothorax tended to occur in an advanced lymphoma.

Another widely debated issue is the necessity to follow dietary measures. $60-70 \%$ of absorbed fats get into the bloodstream through the thoracic duct [9]. The disturbed integrity of the duct wall leads to massive nutritional loss which is most often compensated by the administration of complete parenteral nutrition which provides an additional benefit, i.e. reduced flow of chyle, thus improving the spontaneous healing of the lymphatic system. A low-fat diet is recommended to reduce chyle production. Paradoxically, the shortest treatment period was required by a patient who did not have this dietary measure. This suggests that the crucial role is played by the effective treatment of underlying disease [2, 12]. However, the small number of patiens in our cohort does not allow unambiguous conclusions. In addition, the extent of lymphadenopathy does not correlate with the chylothorax treatment period in our cohort. For instance, a female patient with a $16 \mathrm{~cm}$ retroperitoneal lymphadenopathy was hospitalized for 58 days while a male patient with a small mediastinal and retroperitoneal lymphadenopathy $(2 \mathrm{~cm})$ needed 87 days of hospitalization. Generally, advanced stages of the disease in which chylothorax occurred obviously prevailed (Table 1) $[3,16]$.

For the management of recurrent pleural effusions, an indwelling pleural catheter (IPC) is successfully used [17-19]. Its usefulness is also in the treatment of other conditions including chylothorax [17-19]. The IPC is a tunneled pleural catheter with advantage of allowing patients to be managed in the outpatient setting [19]. Other interventions were chosen in our cohort because of an expected response to adequate treatment and non-palliative management of the underlying disease.

According to the literature, the reduction of chyle production was supported by the administration of somatostatin or octerotide, especially when chylothorax was treated in infants and in patients with traumatic chylothorax [13, 14, 20, 21]. In the case of persistent, so-called 'high volume' chylothorax with a daily chyle loss of more than $1000 \mathrm{ml}$ lasting 5 days $[8,22]$, conversion from conservative to surgical treatment is recommended, most often by ligating the thoracic duct $[1,8,9,22]$ which could be combined with pleurodesis [23]. One of the less frequent approaches applied to non-traumatic tumor-associated chylothorax, is the irradiation of the thoracic duct which was described by Gerstein et al. [15]. Fractional irradiation of the celiac trunk and of the thoracic duct with a dose of $20.4 \mathrm{~Gy}$ and $15 \mathrm{~Gy}$, respectively, resulted in the complete remission of chylothorax in a patient with mediastinal lymphadenopathy that accompanied the lymphoma. The major decrease in drained waste was observed already at a dose as low as $7.5 \mathrm{~Gy}$ [24]. In our cohort, effective doses in the two patients were 9 Gy and 4 Gy [10, 11]. The first patient had CLL with a complicated course of disease (The loss of chyle through thoracic drains during changes in therapeutic regimens is demonstrated in chart No. 1, patient 3.). It is not self-evident whether the improvement of the patient's condition can be attributed to the effect of the treatment of CLL or to the irradiation of the thoracic duct, yet the irradiation of the thoracic duct seems to be a gentle and effective treatment option in persistent chylothorax accompanying malignant lymphoproliferation. Moreover, in our study irradiation was provided in several small doses which enabled further treatment in the future if required.

Radiological approaches have recently become widely used in the treatment of chylothorax. Contrast lymphangiography facilitates a good visualization of the lymphatic system and the chyle leakage site. Furthermore, it is known that contrast lymphangiography also has therapeutic effects as chylothorax becomes suppressed after its application in up to $89 \%$ of the patients [25]. Cope et al. describe a low-risk percutaneous approach for the embolization of the thoracic duct via the cisterna chyli or retroperitoneal lymphatic vessels [24]. Various modifications of transcutaneous embolization approaches are provided by selected centers only [8, 26-30]. Alternative transport procedures indicated in clearly defined situations include introduction of a pleuroperitoneal or pleurovenous shunt, establishing an anastomosis between the thoracic duct and the azygos vein, or transjugular shunt [16, 31-33].

\section{Conclusion}

Based on our experience the crucial factor affecting the clearance of chylothorax appears to consist in suppressing the activity of underlying hematological disease. The median duration of conservatively managed chylothorax in our patients was 73 days. This type of treatment is rather long and demanding and requires patience on the part of both the patient and the medical team. Nevertheless, with the sensitivity of underlying hematological disease to treatment, the general prognosis of the patient is quite good. Our cohort displayed a low risk of recurrence $(20 \%)$ which was linked to relapsed lymphoma only in some of the 
patients. Low-dose irradiation presents an interesting treatment option for refractory chylothorax, which was proven in two patients in the cohort. The future diagnostics and treatment are likely to benefit especially from invasive radiological methods.

\section{Abbreviations \\ CLL: Chronic lymphocytic leukemia; FCR: Fludarabine, cyclophosphamide, rituximab; FL: Follicular lymphoma; LPDs: Lymphoproliferative disorders; MCT: Medium chain triglycerides; M-L: Mediastinal lymphadenopathy; PBSCT: Peripheral blood stem cell transplantation; PTCL-NOS: Peripheral T-cell lymphoma - not otherwise specified; PV: Parenteral nutrition; RCD: Rituximab, cyclophosphamide, high-dose dexamethasone; R-CHOP: Rituximab, cyclophosphamide, doxorubicin, vincristine, and prednisone; R- dex: Rituximab, high-dose dexamethasone; R-ESHAP: Rituximab, etoposide, methylprednisolone, cytarabine, platinium; R-GDP: Rituximab, gemcitabine, dexamethasone, cisplatin; R-L: Retroperitoneal lymphadenopathy; RT: Radiotherapy; SLL: Small lymphocytic lymphoma}

\section{Acknowledgements}

We thank Cyrus Rasti, M.D. for language editing.

\section{Funding}

This work was supported by program PROGRES Q40/08.

\section{Availability of data and materials}

Data avaibility guidance for authors and editors.

\section{Authors' contributions}

All authors read and approved the final manuscript. JP: analyzed and interpreted the patient data regarding the hematological disease and was a major contributor in writing the manuscript. LS: analyzed and interpreted the patient data regarding the hematological disease, language correction. DB, MŠ, MM, AS and PŠ: analyzed and interpreted the patient data regarding the hematological disease. PŽ analyzed and interpreted the patient data regarding the hematological disease and was a major contributor in writing the manuscript, corresponding and senior author.

\section{Ethics approval and consent to participate} Not applicable.

\section{Consent for publication}

Not applicable.

(I submit my manuscript for ethic's committee approval. Result: 16 Aug2018: Ethics Committee composition meets the requirements of ICH GCP standards and is working according to its written procedure which in compliance with the above - mentioned standards (ICH EH6); (Ethics committee, University Hospital Hradec Kralove, Sokolska 581, Hradec Kralove, Czech Rep, Ref number 201808 S19P).

\section{Competing interests}

The authors declare that they have no competing interests.

\section{Publisher's Note}

Springer Nature remains neutral with regard to jurisdictional claims in published maps and institutional affiliations.

\section{Received: 28 August 2018 Accepted: 28 December 2018}

\section{Published online: 09 January 2019}

\section{References}

1. McGrath EE, Blades Z, Anderson PB. Chylothorax: aetiology, diagnosis and therapeutic options. Respir Med. 2010;104(1):1-8.

2. Teng C-L, Li K-W, Yu J-T, Hsu S-L, Wang R-C, Hwang W-L. Malignancyassociated chylothorax: a 20-year study of 18 patients from a single institution. Eur J Cancer Care (Engl). 2012;21(5):599-605.

3. Cortés Télles A, Sandoval R. An unusual presentation of follicular lymphoma. Arch Bronconeumol. 2011;47(1):56-7.
4. Bibby AC, Maskell NA. Nutritional management in chyle leaks and chylous effusions. Br J Community Nurs. 2014;(Suppl Nutrition):S6-8.

5. Rahman NM, Chapman SJ, Davies RJO. Pleural effusion: a structured approach to care. Br Med Bull. 2004;72:31-47.

6. Romero S, Martín C, Hernandez L, Verdu J, Trigo C, Perez-Mateo M, Alemany L. Chylothorax in cirrhosis of the liver: analysis of its frequency and clinical characteristics. Chest. 1998;114(1):154-9.

7. Maldonado F, Hawkins FJ, Daniels CE, Doerr CH, Decker PA, Ryu JH. Pleural fluid characteristics of chylothorax. Mayo Clin Proc. 2009;84(2):129-33.

8. Schild HH, Strassburg CP, Welz A, Kalff J. Treatment options in patients with chylothorax. Dtsch Arzteblatt Int. 2013;110(48):819-26.

9. Selle JG, Snyder WH, Schreiber JT. Chylothorax: indications for surgery. Ann Surg. 1973;177(2):245-9.

10. Van De Voorde L, Vanneste B, Borger J, Troost EGC, Werner P. Rapid decline of follicular lymphoma-associated chylothorax after low dose radiotherapy to retroperitoneal lymphoma localization. Case Rep Hematol. 2014;2014:684689.

11. Haas RLM. Low dose radiotherapy in indolent lymphomas, enough is enough. Hematol Oncol. 2009;27(2):71-81.

12. Mohamed M, Tan J, Kalpurath KK. Non-Hodgkin lymphoma manifesting as massive malignant chylothorax: successful management with chemotherapy and ambulatory drainages using indwelling pleural catheter. Intern Med J. 2015;45(9):980-3.

13. Çakır U, Kahvecioğlu D, Yıldız D, Alan S, Erdeve Ö, Atasay B, Arsan S. Report of a case of neonatal chylothorax that responded to long-term octreotide treatment, and review of the literature. Turk J Pediatr. 2015;57(2):195-7.

14. Ismail NA, Gordon J, Dunning J. The use of octreotide in the treatment of chylothorax following cardiothoracic surgery. Interact Cardiovasc Thorac Surg. 2015;20(6):848-54.

15. Gerstein J, Kofahl-Krause D, Frühauf J, Bremer M. Complete remission of a lymphoma-associated chylothorax by radiotherapy of the celiac trunk and thoracic duct. Strahlenther Onkol Organ Dtsch Rontgengesellschaft Al. 2008; 184(9):484-7.

16. Doerr CH, Allen MS, Nichols FC, Ryu JH. Etiology of chylothorax in 203 patients. Mayo Clin Proc. 2005;80(7):867-70.

17. Jimenez CA, Mhatre AD, Martinez CH, Eapen GA, Onn A, Morice RC. Use of an indwelling pleural catheter for the management of recurrent chylothorax in patients with cancer. Chest. 2007;132(5):1584-90.

18. Faiz SA, Pathania P, Song J, Li L, Balachandran DD, Ost DE, Morice RC, Shannon VR, Bashoura L, Eapen GA, Jimenez CA. Indwelling Pleural Catheters for Patients with Hematologic Malignancies. A 14-Year, SingleCenter Experience. Ann Am Thorac Soc. 2017;14(6):976-85.

19. Bhatnagar R, Maskell NA. Indwelling pleural catheters. Respiration. 2014; 88(1):74-85

20. Lopez-Gutierrez JC, Tovar JA. Chylothorax and chylous ascites: management and pitfalls. Semin Pediatr Surg. 2014;23(5):298-302.

21. Sharkey AJ, Rao JN. The successful use of octreotide in the treatment of traumatic chylothorax. Tex Heart Inst J. 2012;39(3):428-30.

22. Boffa DJ, Sands MJ, Rice TW, Murthy SC, Mason DP, Geisinger MA, Blackstone EH. A critical evaluation of a percutaneous diagnostic and treatment strategy for chylothorax after thoracic surgery. Eur J CardioThorac Surg Off J Eur Assoc Cardio-Thorac Surg. 2008;33(3):435-9.

23. Matsumoto T, Yamagami T, Kato T, Hirota T, Yoshimatsu R, Masunami T, Nishimura T. The effectiveness of lymphangiography as a treatment method for various chyle leakages. Br J Radiol. 2009:82(976):286-90.

24. Cope C, Salem R, Kaiser LR. Management of chylothorax by percutaneous catheterization and embolization of the thoracic duct: prospective trial. J Vasc Interv Radiol JVIR. 1999;10(9):1248-54.

25. Hoffer EK, Bloch RD, Mulligan MS, Borsa JJ, Fontaine AB. Treatment of chylothorax: percutaneous catheterization and embolization of the thoracic duct. AJR Am J Roentgenol. 2001;176(4):1040-2.

26. Nadolski G, Itkin M. Thoracic duct embolization for the management of chylothoraces. Curr Opin Pulm Med. 2013;19(4):380-6.

27. Praveen A, Sreekumar KP, Nazar PK, Moorthy S. Technical note: thoracic duct embolization for treatment of chylothorax: a novel guidance technique for puncture using combined MRI and fluoroscopy. Indian J Radiol Imaging. 2012;22(2):89-92.

28. Nadolski GJ, Itkin M. Thoracic duct embolization for nontraumatic chylous effusion: experience in 34 patients. Chest. 2013;143(1):158-63.

29. Shimmyo T, Morita K, Mineshita M, Tagaya R, Ando K, Mochizuki A, Kurimoto N, Miyazawa T, Osada H, Nakamura H. Pleuroperitoneal shunt for 
chylothorax and chylopericardium in lung cancer: a case report. Ann Thorac Cardiovasc Surg Off J Assoc Thorac Cardiovasc Surg Asia. 2011;17(1):63-6.

30. Artemiou O, Marta G-M, Klepetko W, Wolner E, Müller M-R. Pleurovenous shunting in the treatment of nonmalignant pleural effusion. Ann Thorac Surg. 2003;76(1):231-3.

31. Tanaka N, Mimura M, Ogi K, Amagasa T. Primary malignant melanoma of the oral cavity: assessment of outcome from the clinical records of 35 patients. Int J Oral Maxillofac Surg. 2004;33(8):761-5.

32. Fremont RD, Milstone AP, Light RW, Ninan M. Chylothoraces after lung transplantation for lymphangioleiomyomatosis: review of the literature and utilization of a pleurovenous shunt. J Heart Lung Transplant Off Publ Int Soc Heart Transplant. 2007;26(9):953-5.

33. Lesina B, Aburto M. Octreotide for bilateral chylothorax secondary to lymphoma. Report of one case Rev Med Chil. 2005;133(12):1473-6.

Ready to submit your research? Choose BMC and benefit from:

- fast, convenient online submission

- thorough peer review by experienced researchers in your field

- rapid publication on acceptance

- support for research data, including large and complex data types

- gold Open Access which fosters wider collaboration and increased citations

- maximum visibility for your research: over $100 \mathrm{M}$ website views per year

At $\mathrm{BMC}$, research is always in progress.

Learn more biomedcentral.com/submissions 